\title{
Paternity Deferments and the Timing of Births: U.S. Natality during the Vietnam War
}

\author{
Andrea Kutinova \\ Department of Economics \\ University of Canterbury \\ Private Bag 4800 \\ Christchurch, New Zealand \\ E-mail: andrea.kutinova@canterbury.ac.nz \\ Phone: (+64-3) 3642823 \\ Fax: (+64-3) 3642635
}

\begin{abstract}
During the conflict in Vietnam, married men with dependents could obtain a deferment from the draft. In 1965, following President Johnson's Executive Order 11241 and a subsequent Selective Service System announcement, the particulars of this policy changed substantially in a way which provided strong incentives for childless American couples to conceive a first-born child. This study examines the effects of the intervention on the decision to start a family. In my empirical analysis, I use data from the Vital Statistics for the period 1963-1968 and employ a difference-in-differences methodology. The estimated magnitude of the effect is substantial.
\end{abstract}

JEL Code: J18

I am indebted to Karen Conway, Robert Mohr, Partha Deb, Reagan Baughman, Robert Woodward, and seminar participants at the University of New Hampshire for very helpful suggestions and comments. 


\section{Background}

During the conflict in Vietnam, men between $18 \frac{1}{2}$ and 25 years of age were subject to the draft. Several exemptions to this rule existed. For example, students were exempt. Importantly for the purposes of this study, married men with dependents could also obtain a deferment from the draft, and the particulars of this policy underwent substantial changes in the 1960's. In August 1965, President Johnson issued Executive Order 11241, which formally eliminated deferments for childless men who got married after August 26, 1965, and, in October 1965, the Selective Service declared that childless married men (irrespective of the date of marriage) were to be called up. Both announcements came as a surprise (The New York Times, 1965a). Since married men with children remained exempt, the declarations provided a strong incentive for young couples to conceive a (first-born) child. Before August 1965, marriage had been a sufficient condition for a deferment. Even just a few hours before the August 26 midnight deadline, desperate couples tried to make use of this provision by quickly scheduling their wedding. Between August and October, couples that had missed the deadline had to satisfy an additional condition - conceiving a child. Childless men who got married in this period were still subject to the draft and so had an incentive to conceive a child. In October 1965, the risk of induction was further extended to all couples that had remained childless. Finally, in April 1970, the family deferments were entirely eliminated by Executive Order 11527 (The Selective Service System 2004).

Past research has demonstrated that taxes and expenditure programs can affect fertility (e.g., Whittington et al 1990; see also Milligan 2005 for an excellent review) as 
well as the timing of delivery (Dickert-Conlin and Chandra 1999). The goal of this paper is to provide additional evidence on the responsiveness of childbearing to incentives embedded in public policy by studying a dramatic yet unexamined government intervention - the effects of the Vietnam War paternity deferments on the decision to conceive a first-born child. As discussed in the popular press, Vice President Dick Cheney's first daughter, Elizabeth, was born nine months and two days after the Selective Service System announced that childless married men were to be drafted (The Boston Globe 2000, Slate Chatterbox 2004). Did draft eligible men strategically react to the announcement? And, if so, how widespread and fast was the response?

To my knowledge, no one has investigated the impacts of the Vietnam draft on natality. By using the Vietnam draft rules to identify a causal effect, however, I build on several prior studies. Joshua Angrist, for example, uses the exogeneity of the Vietnam draft rules to identify the effects of military service on lifetime earnings (Angrist 1990, Angrist and Chen 2007) and to measure the racial differences in the value of military service (Angrist 1991). Gullason (1989) and Card and Lemieux (2001, 2002) estimate the effects of the Vietnam draft on schooling explicitly recognizing that college attendance often served as a vehicle to avoid the draft. Both studies find a significant effect of the probability of being drafted on school enrollment.

The fact that the changes in the Selective Service rules were both unexpected and widely publicized makes this an ideal example to study the effects of policy on fertility decisions. Milligan (2005) argues that the assumptions made about the timing of the response to policy are arbitrary since a reaction will be delayed not only by a nine-month gestational lag but also by the time necessary for the diffusion of information about the 
change in policy. In the case examined here, however, the criticism seems less relevant. Newspaper clippings from August 27, 1965 suggest that the issuance of the Executive Order 11241 did receive broad attention. For example, the story was listed on the front pages of The New York Times (1965c) and The Washington Post (1965b). The benefits of becoming a father were made explicit: "From now on, a draft-age man who gets married and becomes a father before being called into service will go into the same deferred class as other fathers." (The Washington Post, 1965b, p. A12) Similarly, on October 27, 1965, one day after the Selective Service declared that childless married men were to be called up, the top U.S. newspapers commented on the policy change (The New York Times, 1965a; The Washington Post, 1965a). ${ }^{1}$ It is reasonable to assume that the general public was well aware of the news.

Also, given the urgency of the situation for the potential draftees, any behavioral response was likely to be fast. In the mid 1960's, the risk of induction facing young American men was increasing dramatically. In the year 1965, when the new policies were announced, the number of men inducted each month increased by more than sixfold from less than 6,000 to nearly 39,000 (Figure 1). And, as anecdotal evidence suggests, young couples were ready to react almost immediately. For example, after President Johnson's Executive Order was issued on August 26, 1965 limiting the eligibility for marital deferments to men married on or before that date, many couples quickly

\footnotetext{
${ }^{1}$ Unfortunately, only a few transcripts of television news are available for years prior to 1968 (Vanderbilt Television News Archive, NBC News Archive, and Burrell's Transcript Service) and none of them is relevant to the issue at hand.
} 
scheduled their wedding in order to beat the midnight deadline (The New York Times, 1965b).

Finally, information about the fecundity of the U.S. population in the early 1960's confirms that young women were, on average, able to conceive a child quickly. In the year 1960, 52\% of Americans 20-24 years old were able to conceive within a month from trying and $77 \%$ were successful within two months (Crist 2004). Thus, a fast and relatively strong reaction to the Executive Order issuance and the Selective Service announcement is realistic.

\section{Data and Methods}

To empirically investigate the effects of the Vietnam draft on natality, I focus on the impacts of President Johnson's Executive Order 11241 and the October 1965 Selective Service announcement and make use of the fact that these policies affected different groups of young men differently. In particular, I use a difference-in-differences type of approach and compare the effects of the policy changes on the behavior of treatment and control groups of young men.

Ideally, all American men in the draft-eligible age would constitute the treatment group. Unfortunately, however, the dataset most suitable for the study - the Vital Statistics of the United States (U.S. Department of Health, Education, and Welfare 196377) - does not provide detailed information on paternal characteristics. ${ }^{2}$ Therefore, I use

\footnotetext{
${ }^{2}$ I have explored several micro datasets but none of them was suitable for this study. For example, the Natality Detail File series only started in the year 1968. The Current Population Survey reports age in years but not the month of birth (making it impossible to focus on children as respondents) and only asks
} 
maternal age as a proxy for the father's age and adjust for the possibility of bias due to misclassification of some women into the treatment and/or control group. A new adjustment method developed in Lewbel (2003) is ideal for the purpose at hand and is described in more detail in "Correction for Misclassification" and the Technical Appendix below. It is worth foreshadowing here that the unadjusted results are conservative since any misclassification into the treatment and/or control group will bias the estimated treatment effect downward.

The Vital Statistics report the number of births for the following age cohorts: under 15 years, 15-19 years, 20-24 years, 25-29 years, 30-34 years, 35-39 years, 40-44 years, 45-49 years, and 50 years and over. In my baseline model, I use women 20-24 years old as the treatment group since only men up to 25 years of age were eligible for the draft and since women, on average, tend to be younger than their partners (Table 1). I exclude teenagers from the baseline analysis since women under 15 years of age were unlikely to be affected by the government policy and since mothers $15-19$ years old seem diverse with respect to their fertility responsiveness (the attitudes towards family planning will likely differ among women in this group). Also, my calculations suggest that between $17.3 \%$ (year 1963) and 26.7\% (year 1968) of mothers 15-19 years old were

females questions related to fertility (making it impossible to link children to their fathers and to focus on fathers as respondents). The National Longitudinal Survey of Young Men (NLSYM) includes information on individuals 14 to 24 years old in the year 1966 but contains no appropriate control group. Also, the sample size in the NLSYM is too small to permit reliable inferences from a stratified analysis (for example, in the summer of 1966, sampled men 19-24 years old had only 22 first-born children). The Childbirth and Adoption History File of the Panel Study of Income Dynamics collected since 1985 does not contain enough first births in the control group to support reliable difference-in-differences estimation. 
single in the period under study. The corresponding estimates are $5.7 \%$ and $8.3 \%$ for mothers 20-24 years old. ${ }^{3}$ In an alternative specification, I add teenagers (15 to 19 years old) to the treatment group. Women 25-29 years old - with husbands likely to be 26 years old or older and thus ineligible for the Vietnam draft - comprise the control group.

To assess the validity of my treatment and control groups, I use the U.S. Natality Detail Files for the years $1969-1971^{4}$ and calculate the percentages of fathers 19 to 25 years old (the draft eligible cohort) by maternal age (Table 2). Maternal age is a reasonably good proxy for paternal age. In particular, $65 \%$ of mothers 20 to 24 years old (the baseline treatment group) had babies with fathers 19 to 25 years old in each of the years 1969,1970 , and 1971 . The corresponding percentage was $68 \%$ for women 15 to 24 years old (an alternative treatment group) and $11 \%$ for mothers in the 25 to 29 year old cohort (the control group). As I discuss shortly, these misclassification probabilities derived from an alternative dataset prove useful in adjusting the baseline difference-indifferences estimates.

Since the existence of children rather than their number played a role in determining draft eligibility, I focus on the birth of a first-born child when estimating the effects of the Executive Order and the Selective Service announcement. Also, the outcome measure needs to be corrected for the overall effects of the war on fertility. In particular, it needs to isolate the potential changes in the number of first births in reaction

\footnotetext{
${ }^{3}$ Source: http://www.cdc.gov/nchs/data/statab/t941x18.pdf, http://www.cdc.gov/nchs/data/statab/t941x19.pdf, http://www.cdc.gov/nchs/data/statab/t941x07.pdf, and http://www.census.gov/popest/archives/pre-1980/PE-11.html; Accessed 03/19/2006.
}

\footnotetext{
${ }^{4}$ These are the first years when the age of both parents was recorded.
} 
to the new deferment rules from the overall changes in natality in a country where many young men had been sent to war. ${ }^{5}$ Therefore, I use the age-specific ratio of the number of first-born infants to all infants (reported by month and year of delivery) as the dependent variable. If the 1965 declarations had a significant effect on the fertility behavior of the potential draftees, the "first-born infants/all infants" ratio should increase in the summer of 1966 (about 9 months after the policy changes were enacted) for women in the treatment group and stay unchanged (or to increase less) for women in the control group. Thus, a comparison of the monthly "first-born infants/all infants" series (purged of a linear time trend and seasonal variation) for the treatment and control groups yields an estimate of the causal relationship between the new government draft policies and fertility. In some of my robustness checks below, I verify that the number of subsequent births is not driving my results. In particular, I directly show that there is no effect of the paternity deferments on the number of subsequent births and also decompose the "first -born infants/all infants" ratio in order to allow for a more flexible functional form. All of these specification checks support the robustness of the baseline results.

More formally, the baseline model is set up as follows:

$$
\mathrm{Y}_{\mathrm{tj}}=\alpha+\beta^{*} \mathrm{~T}_{\mathrm{j}}+\gamma^{*} \mathbf{M}_{\mathrm{t}}+\delta^{*} \mathrm{~T}_{\mathrm{j}}^{*} \mathbf{M}_{\mathrm{t}}+\varepsilon_{\mathrm{tj}}
$$

where $t$ indexes time periods (months from January 1963 to December 1968) and $j$ indexes cohorts (treatment or control). $Y$ is the detrended and deseasonalized "first-born infants/all infants" ratio, $T$ is a dummy variable denoting the treatment group

\footnotetext{
${ }^{5}$ At its peak in April 1969, the U.S. participation in Vietnam involved 543,000 troops (http://www.history.navy.mil/wars/foabroad.htm; Accessed 07/23/2007).
} 
membership (age 20-24 in the baseline specification), and $\boldsymbol{M}$ is a vector of dummy variables, one for each month following the first policy change (August 1965). $T^{*} \boldsymbol{M}$ are interaction dummies denoting the treatment group membership in months following the policy changes, and $\varepsilon$ is an error term. In the above model, the estimated $\delta$ 's on months 9 and 10 after each policy change are the difference-in-differences estimates of interest.

\section{Results}

\section{Descriptive Analysis}

Figure 2 plots the proportions of first births for American women 20 to 24 and 25 to 29 years old by month and year of delivery. From 1963 to 1968, the two ratios grew about linearly with only small deviations from the trend. The series, however, exhibited a spike in the summer of 1966 - approximately nine months after the new draft policies were announced. As hypothesized, the spike was more remarkable for the younger cohort.

Based on the descriptive analysis, it seems reasonable to focus on the relatively stable period from January 1963 to December 1968 when estimating the effects of the new draft policy on fertility. This time period includes several years preceding the Executive Order 11241 issuance (pre-August 1965) as well as several years following the expected effects of the new policies on fertility (post-July/August 1966). Limiting the period studied to the mid-1960's also simplifies the analysis by avoiding the substantial changes to the draft process associated with the introduction of the draft lottery in late 
1969. ${ }^{6}$ Finally, a relatively short follow up is sufficient for studying the immediate decision of affected young couples to conceive a first-born child. Due to the construction of the outcome measure - the proportion of first births to the total number of births investigating long-term fertility dynamics would be complicated as the corrective decrease in the number of first deliveries and an increase in the number of second and subsequent deliveries would be difficult to separate out. For the purposes of this study, year 1968 therefore seems like a reasonable cutoff. Unfortunately, limiting attention to years prior to 1969 excludes the effects of the family deferment elimination of April 1970 from the analysis.

Since the two series of the first-birth ratio likely followed a different (linear) time trend in 1963 to 1968 and since their seasonal pattern might have also differed, appropriate detrending and deseasonalizing had to be performed. A continuous time variable and a full set of month dummies have been used. This approach is similar to that in Card and Lemieux $(2001,2002)$ who regress the annual education outcomes on a linear inter-cohort time trend when estimating the effects of the Vietnam draft on college attendance.

A simple visual examination of the detrended and deseasonalized series (Figure 3) suggests that the government draft policies very likely did have a significant impact on the fertility of the potential draftees. In particular, while the residual ratios for the

\footnotetext{
${ }^{6}$ Beginning in 1970, young men were at risk of induction for only one year rather than for the entire period between ages $181 / 2$ and 25 , as was the case previously. As Card and Lemieux $(2001,2002)$ note, the shortened period of exposure together with the relatively low rate of inductions after 1969 significantly reduced the incentives to pursue draft-avoidance strategies.
} 
treatment and control groups followed a similar time path in the years 1963 to 1965 , the treatment mothers experienced a much sharper increase in the proportion of first births in the summer of 1966. That the control mothers experienced any increase at all may stem from the fact that maternal age is an imperfect proxy for paternal age and so that some of the women in the control group might have also reacted to the draft. As further obvious from Figure 3, the two cohorts of mothers behaved somewhat differently towards the end of the studied period. More specifically, the treatment mothers had a lower residual ratio of first-born babies about 12 and 22 months after the 1966 spike. This is consistent with the fertility behavior (birth spacing in particular) prevalent in the U.S. at that time. Based on data from the Natality Detail Files for the years $1969-1971,{ }^{7}$ the distribution of the length of time between the first and the second live birth peaked at months 13 and 23 in the late 1960's and early 1970's (Figure 4). A decreased number of first births coupled with an increased number of subsequent births in the years 1967 and 1968 by women who had responded to the Vietnam draft by advancing their first delivery to summer 1966 may thus be responsible for the observed pattern.

\section{Regression Results}

To formally estimate the size and significance of the effect of the Vietnam draft rules on natality, I employ a difference-in-differences type of methodology. In the

\footnotetext{
${ }^{7}$ These are the first years when the information on birth spacing was recorded by at least some states. Obtaining this information for the years 1966-1968 would have been preferable since, if the number of first births was exogenously affected by the policy change, birth spacing might have been affected as well. Nevertheless, the stability of the birth spacing distribution in the 1969-1971 period makes extrapolation to the earlier years seem justifiable.
} 
baseline specification of my model, I regress the detrended and deseasonalized "first-born infants/all infants" ratio on a dummy variable set equal to one for the treatment group, seven dummy variables set equal to one for months 8 to 14 after the August 1965 Executive Order issuance (i.e., months 6 to 12 after the October 1965 Selective Service announcement), and seven interaction dummies set equal to one for observations on the treatment group in the exposed months. ${ }^{8}$ If the new policies did induce young women to time the conception of their first-born child in order to make the baby's father exempt from the draft, the coefficients on the interaction dummies for months 9 and 10 after each of the new policies was announced should be positive and statistically significant. In addition, since the announcements were made on August 26 and October 26, 1965, even a quick response by the potential draftees would likely increase the number of infants born in June 1966 (10 months after the Executive Order issuance) and August 1966 (10 months after the Selective Service announcement) by more than the number of infants born in May and July 1966. Therefore, the coefficients on the interaction dummies for months 10 and 12 after the Executive Order issuance (i.e., months 8 and 10 after the October 1965 Selective Service announcement) should be larger in magnitude.

Results from my baseline OLS estimation are reported in the first column of Table 3. Two of the interaction variables are positive and significant at the $95 \%$ confidence level: the interaction dummies for months 10 and 12 after the Executive Order issuance, i.e., months 8 and 10 after the Selective Service announcement. The increased natality in June 1966 very likely represents a direct response to the Executive Order

\footnotetext{
${ }^{8}$ As a robustness check, I have also estimated the main equation with detrending and deseasonalizing in one step. This modification had no substantial impact on the results.
} 
issuance and the increased natality in August 1966 is likely caused by the Selective Service announcement. Even though statistically insignificant, the proportions of first births among treatment women are higher in July, September, and October 1966 as well and the gap diminishes over time.

The second column of Table 3 reports results from a specification where teenagers (mothers 15-19 years old) are added to the treatment group. In this case, the interaction dummies for June, July, August, and September 1966 are all positive, large, and statistically significant. Taken together, the above results thus provide strongly suggestive evidence that the Vietnam War draft policy played a role in determining the timing, and perhaps the number, of births.

\section{Correction for Misclassification}

After estimating the baseline model, I explicitly acknowledge that some women might have been misclassified into the treatment and/or control group. A recent paper (Lewbel 2003) demonstrates that as long as the misclassification probabilities are known to the researcher (for example from a validation sample or from aggregate population proportions), the true average treatment effect can be calculated as: $\tau^{*}=\tau /\left(\mathrm{p}_{0}+\mathrm{p}_{1}-1\right)$, where $\tau$ denotes the estimated (biased) treatment effect, $p_{0}$ is the proportion of untreated individuals in the control group, $p_{1}$ the proportion of truly treated individuals in the treatment group, and $\mathrm{p}_{0}+\mathrm{p}_{1}>1$. (The Technical Appendix includes a more extensive discussion of this result and its use in adjusting my estimates.) As obvious from the above formula, the true treatment effect is zero if and only if the estimated treatment effect is zero. Furthermore, any misclassification into the treatment and/or control group 
will bias the estimated treatment effect downward. Therefore, my estimates of the effect of the deferment rules on natality are conservative. If, for example, $65 \%$ of women in the baseline treatment group and $11 \%$ of women in the control group had babies with men of the draft-eligible age (as suggested by the Natality Detail File estimates), the correct magnitude of the baseline coefficients on the interaction dummies for months 10 and 12 after the Executive Order issuance (i.e., months 8 and 10 after the Selective Service announcement) would be nearly double $\quad(0.016 /(0.89+0.65-1)=0.030$ and $0.017 /(0.89+0.65-1)=0.031$, respectively $)$. Similarly, in the specification where teenagers are added to the treatment group, the corrected statistically significant coefficients (months 10 to 13 after the Executive Order issuance) would be 0.040, 0.025, 0.037, and 0.026 , respectively.

To attach meaning to these estimates, I calculate the predicted increase in the number of births. First, I consider the baseline case with no correction for misclassification. Using the actual number of deliveries obtained from the Vital Statistics suggests that the number of first births increased by 6,488 as a result of the new draft policy announcements. ${ }^{9}$ Next, using the corrected treatment effects and recognizing that $65 \%$ of mothers $20-24$ years old and $11 \%$ of mothers $25-29$ years old were "at risk" modifies the estimate to 8,283 . And, finally, using the baseline estimates but taking into

\footnotetext{
${ }^{9}$ Let $Y_{1}$ denote the number of first births, $Y_{2}$ the number of subsequent births, and $Z$ the policy change of interest. Then, $\tau=\partial\left[\mathrm{Y}_{1} /\left(\mathrm{Y}_{1}+\mathrm{Y}_{2}\right)\right] / \partial \mathrm{Z}=\left[\left(\partial \mathrm{Y}_{1} / \partial \mathrm{Z}\right) *\left(\mathrm{Y}_{1}+\mathrm{Y}_{2}\right)-\mathrm{Y}_{1} *\left(\partial \mathrm{Y}_{1} / \partial \mathrm{Z}+\partial \mathrm{Y}_{2} / \partial \mathrm{Z}\right)\right] /\left(\mathrm{Y}_{1}+\mathrm{Y}_{2}\right)^{2}$, where $\partial \mathrm{Y}_{2} / \partial \mathrm{Z}$ is assumed to be 0 (this assumption is verified in my analysis of subsequent births). Thus, $\partial \mathrm{Y}_{1} / \partial \mathrm{Z}$ $=\tau^{*}\left(\mathrm{Y}_{1}+\mathrm{Y}_{2}\right)^{2} / \mathrm{Y}_{2}$. Using the actual numbers of first and subsequent births to women 20-24 years old reported in the Vital Statistics yields: $\partial \mathrm{Y}_{1} / \partial \mathrm{Z}=\left(0.016 * 107,042^{2} / 61,796=\right) 2,967$ (June 1966) + $\left(0.017 * 116,886^{2} / 65,966=\right) 3,521$ (August 1966) $=6,488$.
} 
account that a fraction of the teenage group could have been affected by the new draft policies further increases the predicted effect to 15,532 .

When teenagers are directly added to the treatment group, the magnitude of the estimated effect increases further. In particular, my results indicate that the number of first births might have increased by as many as 19,540 in June and August 1966. In fact, when all the statistically significant coefficients from the alternative specification are employed, the predicted number of additional first births delivered between June and September 1966 rises to 32,914 .

\section{Robustness Checks}

To check the robustness of the baseline results, several alternative specifications of the difference-in-differences model are estimated. ${ }^{10}$ First, I add dummy variables for all the remaining months after the Executive Order issuance as well as their interactions with the treatment dummy to the baseline regression. This way, the Executive Order of August 1965 and the Selective Service announcement of October 1965 are allowed to have an effect on fertility throughout the entire period from September 1965 to December 1968. Results from this specification are very similar to those reported in the first column of Table 3 .

Next, I consider the possibility that the trend in the "first-born infants/all infants" ratio was not linear (for either the treatment or the control cohort) in the mid-1960's. To allow for this possibility, I follow Card and Lemieux $(2001,2002)$ and add a quadratic time variable to the simple linear time term and the full set of month dummies when

\footnotetext{
${ }^{10}$ Results from all alternative estimations are available upon request.
} 
detrending and deseasonalizing the original series. I then use the residuals from this analysis in the difference-in-differences type of model. The magnitude of the coefficients on the interaction dummies of interest (10 months after each of the policy changes) decreases only very slightly and both variables remain highly statistically significant. None of the other interaction dummies reaches statistical significance at the $95 \%$ confidence level. As before, the main conclusions do not change when the full model (with dummies for all months after September 1965) is estimated.

To verify the causality of the relationship, I also estimate the above models for a counterfactual - an artificial (i.e., unreal) policy change. In particular, I assume that instead of being announced in the summer of 1965, the new draft rules were announced, alternatively, in the summer of 1962, 1963, 1964, 1966, or 1967. As hypothesized, the policy coefficients of interest never approach statistical significance in these models.

Further, to verify that the number of subsequent births is not driving my results, I use the number of subsequent births instead of the "first-born infants/all infants" ratio as the dependent variable. As expected, there is no difference between the treatment and control groups of mothers following the policy changes.

Also, since the use of the "first-born infants/all infants" ratio imposes a functional restriction on the model, I replace this variable with the number of first birth and add the number of subsequent births as well as its interaction with the treatment group membership on the right-hand side (Table 4; note that the number of all births cannot be used due to endogeneity). Both of the new regressors are positive and highly statistically significant but the main results remain qualitatively the same. The magnitude of the estimates is very similar as well. In particular, the new results indicate that the number of 
first births increased by 2,576 and 3,759 in June and August 1965, respectively. The sum of these two effects, i.e., 6,355 additional first births, is very close to the 6,488 additional births predicted by the baseline model (without correction for misclassification). ${ }^{11}$

Finally, in order to formally test the joint hypothesis that the proportion of first births increased significantly in months 9 and 10 after each of the policy changes, I replace the individual dummies for months 9 to 12 after the Executive Order issuance (i.e., months 7 to 10 after the October 1965 Selective Service announcement) by a single dummy variable. As expected, the coefficient on this variable interacted with the treatment group membership is large and highly statistically significant $\left(\delta^{\wedge}=0.010\right.$, $\mathrm{SE}=0.004$ for the baseline treatment group and $\delta \wedge=0.017, \mathrm{SE}=0.004$ for the treatment group including teenagers). Other coefficients in the model are unaffected by this change.

\section{Conclusions}

The magnitude of the effect of the Vietnam War paternity deferments on the decision to start a family estimated in this paper is quite substantial. In particular, the calculated conservative increase in the number of first births by 15,532 in June and August 1966 represents over $7 \%$ of the total number of first deliveries in those two

\footnotetext{
${ }^{11}$ I have also considered using a birth rate as the dependent variable. Unfortunately, monthly population estimates for the 1960s are not available (U.S. Census Bureau). Therefore, a birth rate would need to use annual population estimates in the denominator. Since the effects of the paternity deferment policies seem to be month-specific - concentrated 10 months after their enactment - adding annual population estimates to the dependent variable would not contribute to the estimation of this 10-month lag.
} 
months. It also corresponds to about $28 \%$ of the Selective Service System calls for inductees in those months (The Selective Service System 1968). This finding adds to a growing body of evidence that government interventions may indeed affect individuals' reproductive behavior. It also adds to the list of potentially long lasting effects of the Vietnam War draft policies.

How does this effect compare to the effects of monetary child benefits? A good comparator is provided by Milligan (2005) who studies the fertility effects of the Allowance for Newborn Children (ANC) implemented between 1988 and 1997 in Quebec. Milligan's results seem particularly relevant because the ANC, like the paternity deferments studied here but unlike tax incentives and welfare benefits studied elsewhere, provided a universal child benefit independent of income but dependent on the number of previously born children. Also, Milligan (2005) finds a greater fertility responsiveness to financial incentives than AFDC studies and so allows for a conservative estimate of the relative effect of paternity deferments as compared to monetary child benefits.

In Milligan (2005), a newborn lump sum benefit of C $\$ 1,000$ increases the probability that a childless woman of reproductive age will have a first child by $24.3 \%$. In 1966, there were 1,007,324 first births to $15-24$ year old women in the U.S. As calculated in this study, at least 15,532 of those births are attributable to the paternity deferments, representing an increase of 1.6\%. Using Milligan's results, the same effect could be achieved by paying $\left(\$ C 1,000^{*} 1.6 / 24.3=\right)$ C $\$ 66$ per child or over $\mathrm{C} \$ 66$ million for all the 1,007,324 first children born to mothers 15-24 years old in 1966. Using year 1995 exchange rate of C\$ 1.37 for US\$ 1.00 suggested in Milligan (2005) and converting 
to 2006 dollars, the payment required to produce the same increase in births as that attributable to the Vietnam War paternity deferments would be US\$ 64 million.

An interesting question that remains is to what extent the increase in the number of births in the summer of 1966 translated into an increase in completed fertility and to what extent it represented a mere change in birth timing. Unfortunately, this issue is difficult to address with existing data. In an attempt to study subsequent fertility of women affected by the Vietnam draft, I have examined a sample from the 5\% Public-Use Microdata Sample (PUMS) from the 1980 U.S. Census. Women who were 20-24 years old in summer 1966 were 33-37 years old on the Census Day of April 1 ${ }^{\text {st }}, 1980$. I have created a subset of this group consisting of women who were 'householders' or 'spouses' in a family or 'spouses' or 'parents' in a subfamily where a child born between April and September (quarters 2 and 3) of 1966 was present. ${ }^{12}$ Since these children were 13 years old on the Census Day, they were still likely to be residing with their parents and so recorded in the PUMS dataset. As defined in the 1980 Census, a 'child' refers to an own child, an adopted child, or a stepchild. Therefore, I have limited my study group to women who had also had at least one previous birth. This left 30,869 women in the study group and 365,884 women in the comparison group.

A problem with comparing fertility behavior of women who had a child in spring or summer 1966 with their same-age counterparts who did not have a child in this period is that women who chose to become pregnant at age 20-24 are likely to differ systematically from other women in a way which affects their subsequent fertility behavior. Indeed, as my data show, women who had started with childbearing early in life had higher fertility by age 33-37 than women in the comparison group (3.2 vs. 2.1

\footnotetext{
${ }^{12}$ This method of matching children with mothers is similar to Angrist and Evans (1998).
} 
children, respectively). To mitigate this problem, I have selected a 'straw man' group from my sample and examined completed fertility of 33-37 year-old women who had conceived before the new deferment policies were announced and had a child in JanuaryMarch (quarter 1) of 1966. As expected, these 13,744 women were slightly older than those delivering in April-September 1966 (35.13 vs. 35.09 years), were more likely to be Black (14.4 vs. $12.5 \%$ ), and less likely to have completed high school (71.5 vs. $73.6 \%)$. However, the mean fertility of both groups was 3.2 children and even when controlling for age, race, and high school education, there was no statistical difference. So, women who had a child in January-September 1966 clearly differ from their counterparts who did not have a child in this period but I could not detect any difference between women who were potentially affected by the new deferment policies and women who were not. While this could theoretically mean that women reacting to the policies adopted fertility behavior of those choosing to start childbearing at a young age, it more likely reflects the fact that the fraction of affected women in the study group is very small. In particular, the 30,869 study women in the PUMS data represent 617,380 American women. Since the predicted increase of 15,532 births attributed to the paternity deferments in this paper corresponds to only $2.5 \%$ of the overall population, it is unlikely that a cohort analysis would reveal significant differences even if they existed.

The Census analysis has a couple of additional limitations. First, I could not distinguish between own children and adopted or step-children. Second, not all of the children used to construct the study sample were necessarily first-born children. Unfortunately, older children might have already left the household (and the dataset). Third, the PUMS data only reports the quarter - not the month - of birth. As a result, the 
window of April-September 1966 is wider than the period in which the effects of the paternity deferments were concentrated (i.e., June-August 1966). These problems can be avoided by examining the CPS 1995 Fertility and Marital History Supplement. From this dataset, I obtained the distribution of the lifetime number of births (completed fertility) for women 20-24 years old at their first delivery whose first child was born in the summer of 1966. I then compared this distribution to the corresponding distributions for women whose first delivery occurred in the summers of 1962-1965 and 1967-1970. Unfortunately, the number of observations (about 80 each year - 753 in total) was too low to enable reliable comparisons. Furthermore, the methodology used here and in the Census analysis above made it impossible to study the proportion of women with no births. This is an important limitation since, as Ananat et al. (2004) note, zero is the only point in the fertility distribution for which there is an unambiguous prediction: in the case examined here, the proportion of childless women should fall. Following Ananat et al. (2004), I have therefore considered a complementary approach. In particular, I have used the method of cohort analysis to study completed fertility of women 10-14, 15-19, 20-24 (the exposed group), 25-29, and 30-34 years old in the year 1966. For the purposes at hand, however, this analysis proved too crude as the general decline in fertility over time strongly dominated any other fertility pattern.

While it is not clear whether the paternity deferments affected completed fertility or the timing of birth, the consequences of either change - in terms of maternal education, labor market behavior, marital decisions, maternal and child health, and other outcomes could be important. For example, Rosenzweig and Schultz (1985) demonstrate that the effects of family size on female labor market outcomes can be significant. Angrist and 
Evans (1998) corroborate this finding and show that fertility reduces female labor supply especially among poor and less educated women. Moreover, previous literature indicates that circumstances surrounding first birth specifically are important. For example, using the National Longitudinal Survey, Shapiro and Mott (1994) show that the employment behavior surrounding first births in 1968-1973 is an important independent predictor of female lifetime work experience. Jacobsen et al (1999) use the 1970 and 1980 U.S. Census data on married nulliparous women who gave birth to twins. Using the twin child as an unplanned additional birth, they find that unplanned first births reduce female labor supply and earnings.

Focusing on the consequences of teenage pregnancy, McElroy (1996) finds that having a birth as a teenager reduces the likelihood of high school completion and college enrollment even after controlling for observable factors that account for the lower socioeconomic status of teenage mothers during their childhood. Hotz et al (2005) use miscarriages as an instrument to better control for the endogeneity of having a birth as a teenager. They conclude that early childbearing does decrease high school completion but the effect is smaller than previously believed.

With respect to the timing of birth and health, Royer (2004) investigates the effects of maternal age on birth outcomes. Comparing outcomes across siblings born in Texas between 1989 and 2001, she concludes that "the 'best' age for first and second births is between 22 and 25 " (p. 24) and that younger and older mothers face an elevated risk of preterm delivery, infant death, and child's abnormal condition. Thus, 20-24 yearold women are at an ideal age for childbearing but to the extent the paternity deferments induced births among teenagers, they might have had a detrimental effect on infant 
health. Overall, the indirect evidence available suggests that by influencing natality, the draft deferments likely had other long lasting effects. 


\section{Bibliography}

Ananat, Elizabeth Oltmans, Jonathan Gruber, and Phillip B. Levine, “Abortion

Legalization and Lifecycle Fertility,” NBER Working Paper No. 10705 (2004).

Angrist, Joshua D., "Lifetime Earnings and the Vietnam Era Draft Lottery: Evidence from Social Security Administrative Records," The American Economic Review 80:3 (1990), 313-336.

Angrist, Joshua D., "The Draft Lottery and Voluntary Enlistment in the Vietnam Era," Journal of the American Statistical Association 86:415 (1991), 584-595.

Angrist, Joshua D. and Stacey H. Chen, "Long-Term Consequences of Vietnam-Era Conscription: Schooling, Experience, and Earnings," NBER Working Paper No. 13411 (2007).

Angrist, Joshua D. and William N. Evans, “Children and Their Parents' Labor Supply: Evidence from Exogenous Variation in Family Size," American Economic Review 88:3 (1998), 450-77.

Baughman, Reagan and Stacy Dickert-Conlin, "Did Expanding the EITC Promote Motherhood?," American Economic Review 93:2 (2003), 247-251. 
The Boston Globe, "Republican Ticket Lets a Military Connection Slip,” The Boston Globe (2000)

(http://www.boston.com/news/politics/president/bush/articles/2000/07/28/republican_tick et_lets_a_military_connection_slip; Accessed 10/03/2004).

Card, David and Thomas Lemieux, "Going to College to Avoid the Draft: The Unintended Legacy of the Vietnam War," The American Economic Review 91:2 (2001), $97-102$.

Card, David and Thomas Lemieux, "Did Draft Avoidance Raise College Attendance During the Vietnam War?,” Working Paper No. 46, Center for Labor Economics, University of California, Berkeley, California (2002).

Crist, Thomas O., "Life Table Problem Set" (2004)

(http://zoology.muohio.edu/crist/zoo204/Life_Table2.html; Accessed 11/03/2004).

Dickert-Conlin, Stacy and Amitabh Chandra, "Taxes and the Timing of Births," The Journal of Political Economy 107:1 (1999), 161-177.

Gullason, Edward T., "The Consumption Value of Schooling: An Empirical Estimate of One Aspect," The Journal of Human Resources 24:2 (1989), 287-298. 
Hotz, Joseph V., Susan Williams McElroy, and Seth G. Sanders, "Teenage Childbearing and Its Life Cycle Consequences: Exploiting a Natural Experiment," The Journal of Human Resources 40:3 (2005), 683-715.

Jacobsen, Joyce P., James Wishart Pearce III, and Joshua L. Rosenbloom, "The Effects of Childbearing on Married Women's Labor Supply and Earnings: Using Twin Births as a Natural Experiment," Journal of Human Resources 34:3 (1999), 449-74.

Lewbel, Arthur, "Estimation of Average Treatment Effects with Misclassification," Boston College Working Paper in Economics No. 556 (2003).

McElroy, Susan Williams, "Early Childbearing, High School Completion, and College Enrollment: Evidence from 1980 High School Sophmores," Economics of Education Review 15:3 (1996), 303-324.

Milligan, Kevin, "Subsidizing the Stork: New Evidence on Tax Incentives and Fertility," Review of Economics and Statistics 87:3 (2005), 539-55.

National Center for Health Statistics, Centers for Disease Control and Prevention, Vital Statistics of the United States 1963-1968, Volume 3: Marriage and Divorce. (1967-71) (http://www.cdc.gov/nchs/products/pubs/pubd/vsus/1963/1963.htm; Accessed 11/03/2004). 
Rosenzweig, Mark R. and Paul T. Schultz, "The Demand for and Supply of Births:

Fertility and Its Life Cycle Consequences," American Economic Review 75:5 (1985), 992-1015.

Royer, Heather N., "What All Women (and Some Men) Want to Know: Does Maternal Age Affect Infant Health?," University of California, Berkley, Center for Labor Economics Working Paper No. 68 (2004).

Shapiro, David and Frank L. Mott, "Long-Term Employment and Earnings of Women in Relation to Employment Behavior Surrounding the First Birth," Journal of Human Resources 29:2 (1994), 248-75.

The New York Times, "Draft Expected to Call Students and Married Men," The New York Times October 27 (1965a), 1 and 4.

The New York Times, "Many Seek to Beat Deadline," The New York Times August 27 (1965b), 10.

The New York Times, "New Husbands Face Draft As Exemption Is Removed," The New York Times August 27 (1965c), 1 and 10.

The Selective Service System, Office of Public and Intergovernmental Affairs (http://www.sss.gov; Accessed 09/18/2004) 
The Selective Service System, Annual Report of the Director of Selective Service for the Fiscal Year 1967 to the Congress of the United States (Washington, DC: U.S. Government Printing Office, 1968).

Slate Chatterbox, "Elizabeth Cheney, Deferment Baby; How Dick Cheney Dodged the Vietnam Draft,” Slate Chatterbox (2004) (http://slate.msn.com/id/2097365; Accessed 09/16/2004).

U.S. Department of Health, Education, and Welfare, Vital Statistics of the United States 1961-1975, Volume 1: Natality (Washington, D.C.: U.S. Department of Health, Education, and Welfare, 1963-77).

U.S. Dept. of Health and Human Services, National Center for Health Statistics, Natality Detail File, 1969-71 (Hyattsville, MD: US Dept. of Health and Human Services, National Center for Health Statistics [producer], 1970-72. Ann Arbor, MI: Inter-university Consortium for Political and Social Research [distributor], 2002).

The Washington Post, "Maryland Plans Draft of Husbands," The Washington Post October 27 (1965a), B1.

The Washington Post, "Draft Delays Ended for Newlywed," The Washington Post August 27 (1965b), A12. 
Whittington, Leslie A., James Alm, and Elizabeth Peters, "Fertility and the Personal Exemption: Implicit Pronatalist Policy in the United States," American Economic Review $80: 3$ (1990), 545-56. 
Figure 1.

Monthly Number of Inductions

United States, 1963-1966

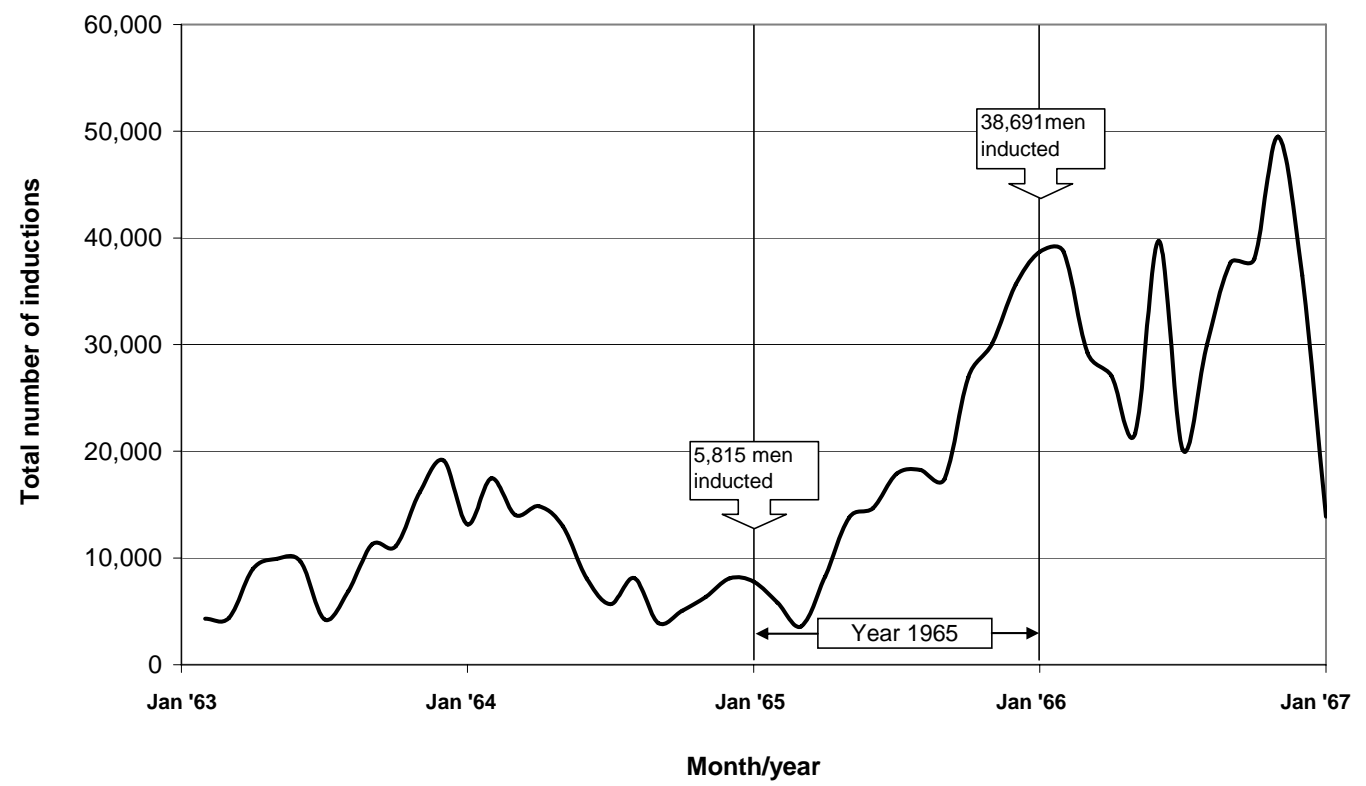

Source: The Selective Service System 1968 
Figure 2.

\section{Proportion of 1st Births by Month and Year of Birth United States, 1961-1970}

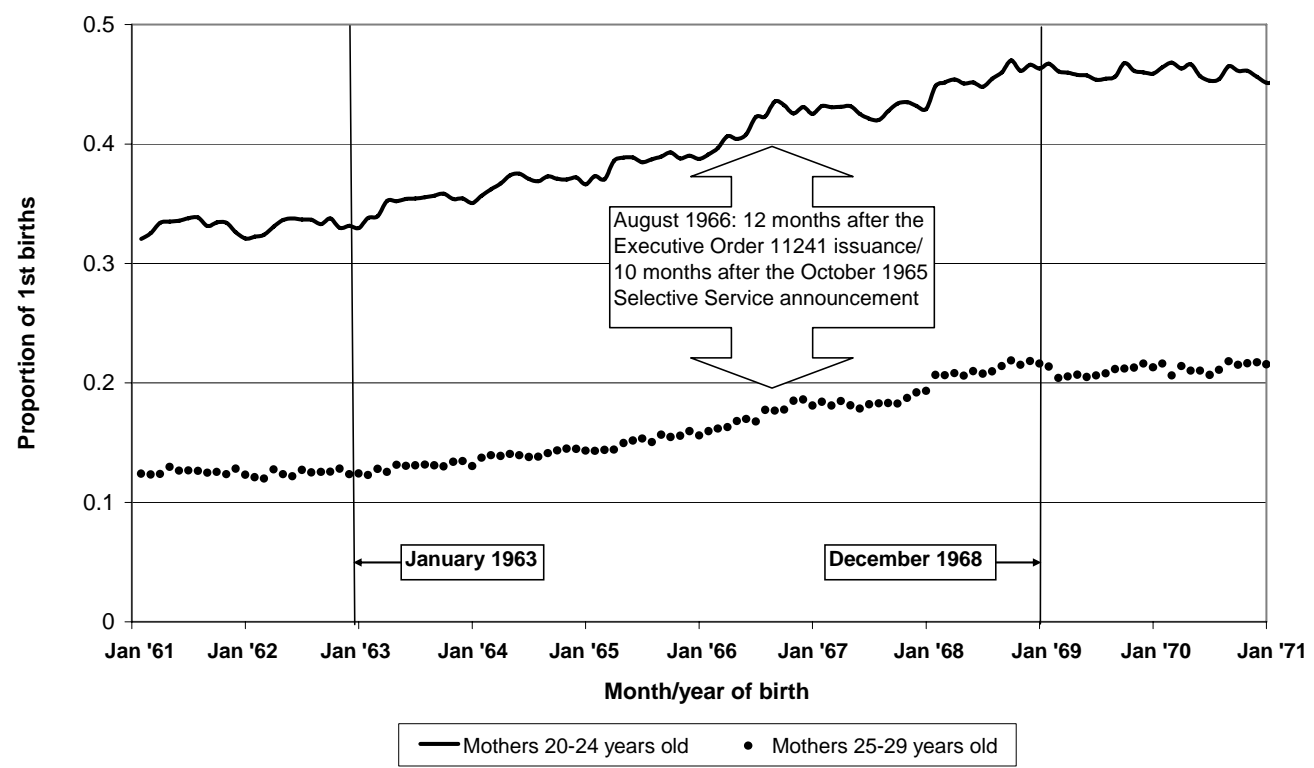


Figure 3.

Proportion of 1st Births by Month and Year of Birth United States, 1963-1968; Detrended and Deseasonalized

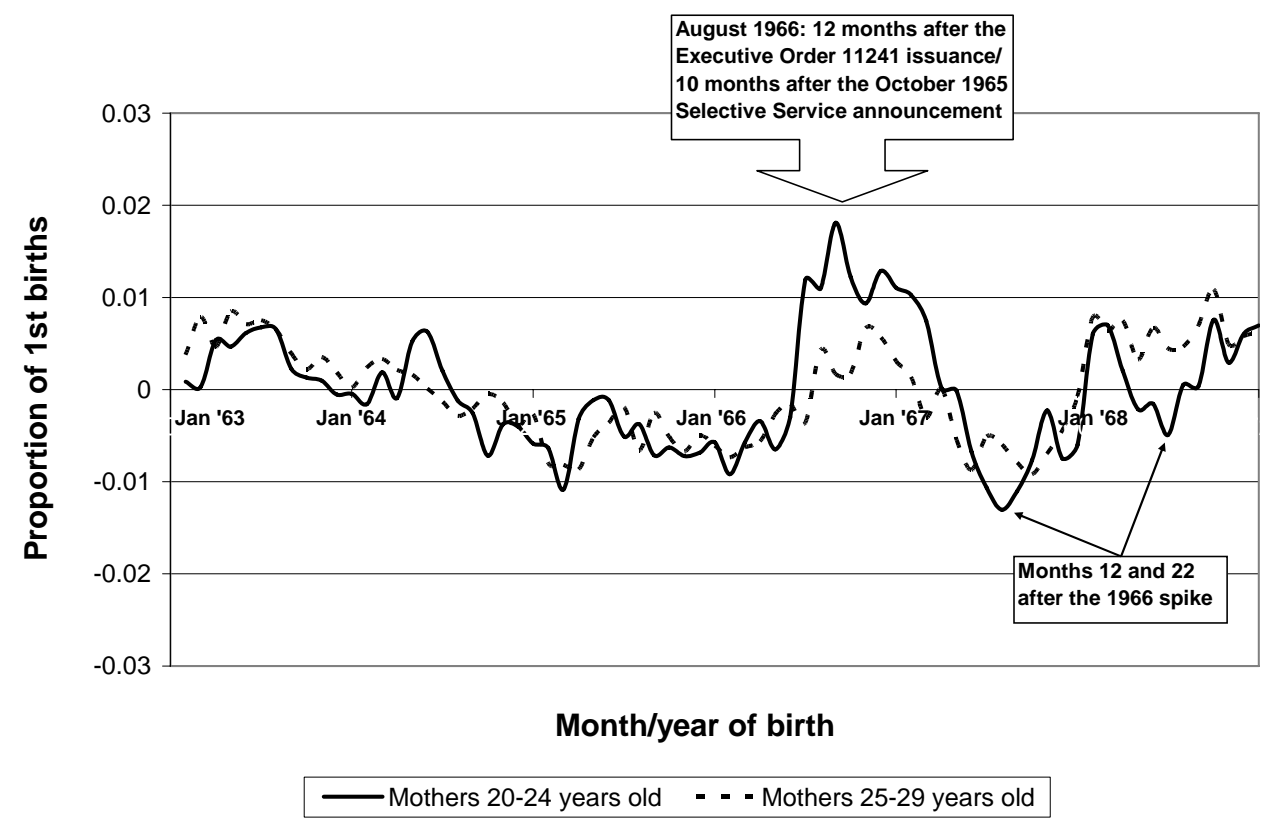


Figure 4.

Interval Since Last Live Birth for Second Births United States, 1969-1971

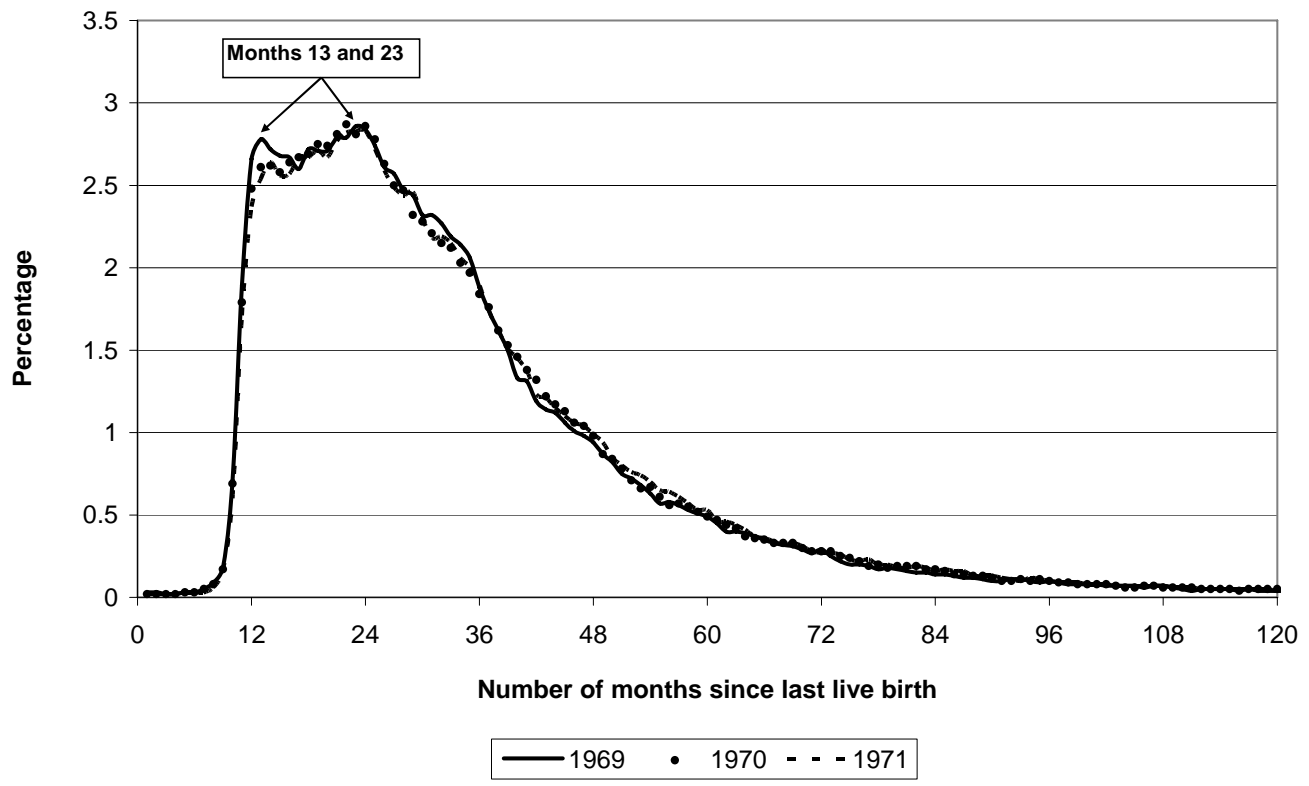

Source: Natality Detail Files 1969-1971 
Table 1. Median Age of Brides and Grooms at the Time of First Marriage United States, 1963-1968

\begin{tabular}{lccc}
\hline Year & Median age of brides & Median age of grooms & Difference in median age \\
\hline 1963 & 20.3 & 22.5 & 2.2 \\
1964 & 20.5 & 23.0 & 2.5 \\
1965 & 20.4 & 22.5 & 2.1 \\
1966 & 20.3 & 22.6 & 2.3 \\
1967 & 20.8 & 22.9 & 2.1 \\
1968 & 20.6 & 22.4 & 1.8 \\
\hline
\end{tabular}

Source: National Center for Health Statistics, CDC (1967-71) 
Table 2. Percentages of Fathers 19 to 25 Years Old by Mother's Age United States, 1969-1971

\begin{tabular}{lcccc}
\hline Year & & $\mathbf{1 9 6 9}$ & $\mathbf{1 9 7 0}$ & $\mathbf{1 9 7 1}$ \\
\hline \% missing info on father's age & 9.18 & 9.70 & 9.89 \\
\hline $\begin{array}{l}\text { Mother's age } \\
\text { cohort }\end{array}$ & 20 to 24 years old (baseline treatment group) & 64.82 & 65.10 & 65.46 \\
& 15 to 24 years old (alternative treatment group) & 68.30 & 68.33 & 68.62 \\
& 25 to 29 years old (control group) & 11.18 & 10.84 & 11.20 \\
\hline
\end{tabular}

Source: U.S. Dept. of Health and Human Services, National Center for Health Statistics (1970-72) 
Table 3. The Effects of the Vietnam War Paternity Deferments on the Proportion of 1st Births; United States, 1963-1968; OLS Estimation

\begin{tabular}{|c|c|c|}
\hline \multirow[t]{2}{*}{ Variable } & \multicolumn{2}{|c|}{ Parameter estimate } \\
\hline & $\begin{array}{c}\text { Baseline } \\
\text { treatment } \\
\text { group (20-24 } \\
\text { years old) }\end{array}$ & $\begin{array}{c}\text { Alternative } \\
\text { treatment } \\
\text { group (15-24 } \\
\text { years old) } \\
\end{array}$ \\
\hline Treatment cohort & $\begin{array}{l}-0.001 \\
(0.001) \\
\end{array}$ & $\begin{array}{l}-0.001 \\
(0.001) \\
\end{array}$ \\
\hline 8 months after the Executive Order 11241 issuance/ 6 months after the & -0.003 & -0.003 \\
\hline October 1965 Selective Service announcement & $(0.006)$ & $(0.005)$ \\
\hline 9 months after the Executive Order 11241 issuance/ 7 months after the & -0.001 & -0.001 \\
\hline October 1965 Selective Service announcement & $(0.006)$ & $(0.005)$ \\
\hline 10 months after the Executive Order 11241 issuance/ 8 months after & -0.004 & -0.004 \\
\hline the October 1965 Selective Service announcement & $(0.006)$ & $(0.005)$ \\
\hline 11 months after the Executive Order 11241 issuance/ 9 months after & 0.004 & 0.004 \\
\hline the October 1965 Selective Service announcement & $(0.006)$ & $(0.005)$ \\
\hline 12 months after the Executive Order 11241 issuance/ 10 months after & 0.002 & 0.002 \\
\hline the October 1965 Selective Service announcement & $(0.006)$ & $(0.005)$ \\
\hline 13 months after the Executive Order 11241 issuance/ 11 months after & 0.002 & 0.002 \\
\hline the October 1965 Selective Service announcement & $(0.006)$ & $(0.005)$ \\
\hline 14 months after the Executive Order 11241 issuance/ 12 months after & 0.007 & 0.007 \\
\hline the October 1965 Selective Service announcement & $(0.006)$ & $(0.005)$ \\
\hline 8 months after the Executive Order 11241 issuance/ 6 months after the & -0.003 & 0.007 \\
\hline October 1965 Selective Service announcement $*$ Treatment cohort & $(0.008)$ & $(0.008)$ \\
\hline 9 months after the Executive Order 11241 issuance/ 7 months after the & -0.001 & 0.011 \\
\hline October 1965 Selective Service announcement $*$ Treatment cohort & $(0.008)$ & $(0.008)$ \\
\hline 10 months after the Executive Order 11241 issuance/ 8 months after & $0.016^{* *}$ & $0.023 * * *$ \\
\hline the October 1965 Selective Service announcement * Treatment cohort & $(0.008)$ & $(0.008)$ \\
\hline 11 months after the Executive Order 11241 issuance/ 9 months after & 0.007 & $0.014 *$ \\
\hline the October 1965 Selective Service announcement * Treatment cohort & $(0.008)$ & $(0.008)$ \\
\hline 12 months after the Executive Order 11241 issuance/ 10 months after & $0.017 * *$ & $0.021 * * *$ \\
\hline the October 1965 Selective Service announcement $*$ Treatment cohort & $(0.008)$ & $(0.008)$ \\
\hline 13 months after the Executive Order 11241 issuance/ 11 months after & 0.011 & $0.015^{* *}$ \\
\hline the October 1965 Selective Service announcement $*$ Treatment cohort & $(0.008)$ & $(0.008)$ \\
\hline 14 months after the Executive Order 11241 issuance/ 12 months after & 0.003 & 0.005 \\
\hline the October 1965 Selective Service announcement $*$ Treatment cohort & $(0.008)$ & $(0.008)$ \\
\hline
\end{tabular}

The dependent variable is the linearly detrended and deseasonalized proportion of first births to all U.S. births (144 observations). An intercept term (not statistically significant) was included in the model.

Standard errors are given in parentheses. $* * *, * *$, and $*$ denote statistical significance at the $99 \%, 95 \%$, and $90 \%$ confidence levels, respectively. 
Table 4. The Effects of the Vietnam War Paternity Deferments on the Number of 1st Births; United States, 1963-1968; OLS Estimation

\begin{tabular}{|c|c|}
\hline Variable & $\begin{array}{c}\text { Parameter estimate } \\
\text { Baseline treatment group } \\
\text { (20-24 years old) }\end{array}$ \\
\hline Treatment cohort & $\begin{array}{c}455.19 \\
(6423.44)\end{array}$ \\
\hline Number of subsequent births & $\begin{array}{l}0.31 * * * \\
(0.05)\end{array}$ \\
\hline Number of subsequent births* Treatment cohort & $\begin{array}{c}0.35^{* * *} \\
(0.09) \\
\end{array}$ \\
\hline 8 months after the Executive Order 11241 issuance/ 6 months after the & -20.28 \\
\hline October 1965 Selective Service announcement & $(950.42)$ \\
\hline 9 months after the Executive Order 11241 issuance/ 7 months after the & 419.63 \\
\hline October 1965 Selective Service announcement & $(978.87)$ \\
\hline $\begin{array}{l}10 \text { months after the Executive Order } 11241 \text { issuance/ } 8 \text { months after } \\
\text { the October } 1965 \text { Selective Service announcement }\end{array}$ & $\begin{array}{l}140.84 \\
(969.92)\end{array}$ \\
\hline 11 months after the Executive Order 11241 issuance/ 9 months after & 1358.64 \\
\hline 12 months after the Executive Order 11241 issuance/ 10 months after & 862.29 \\
\hline the October 1965 Selective Service announcement & $(982.75)$ \\
\hline 13 months after the Executive Order 11241 issuance/ 11 months after & 841.22 \\
\hline the October 1965 Selective Service announcement & $(976.81)$ \\
\hline 14 months after the Executive Order 11241 issuance/ 12 months after & 1357.21 \\
\hline the October 1965 Selective Service announcement & $(978.84)$ \\
\hline 8 months after the Executive Order 11241 issuance/ 6 months after the & -1256.40 \\
\hline October 1965 Selective Service announcement * Treatment cohort & $(1344.63)$ \\
\hline 9 months after the Executive Order 11241 issuance/ 7 months after the & -966.06 \\
\hline October 1965 Selective Service announcement * Treatment cohort & $(1379.01)$ \\
\hline 10 months after the Executive Order 11241 issuance/ 8 months after & $2576.34 *$ \\
\hline the October 1965 Selective Service announcement * Treatment cohort & $(1391.64)$ \\
\hline 11 months after the Executive Order 11241 issuance/ 9 months after & 1476.56 \\
\hline the October 1965 Selective Service announcement * Treatment cohort & $(1446.25)$ \\
\hline 12 months after the Executive Order 11241 issuance/ 10 months after & $3758.99 * * *$ \\
\hline the October 1965 Selective Service announcement * Treatment cohort & $(1407.67)$ \\
\hline 13 months after the Executive Order 11241 issuance/ 11 months after & $2430.89 *$ \\
\hline the October 1965 Selective Service announcement * Treatment cohort & $(1382.85)$ \\
\hline 14 months after the Executive Order 11241 issuance/ 12 months after & 1134.80 \\
\hline the October 1965 Selective Service announcement $*$ Treatment cohort & $(1372.37)$ \\
\hline
\end{tabular}

The dependent variable is the linearly detrended and deseasonalized number of first U.S. births (144 observations). An intercept term was included in the model. Standard errors are given in parentheses. *** and $*$ denote statistical significance at the $99 \%$ and $90 \%$ confidence levels, respectively. 


\section{Technical Appendix: Estimation of Average Treatment Effects with Misclassification}

Based on: Lewbel, Arthur. 2003. "Estimation of Average Treatment Effects with Misclassification," Working Paper. (Especially "Identification by Known Misclassification Probabilities" - pp. 5-8 and "Proof of Theorem 1" - pp. 24-25) - http://www2.bc.edu/ lewbel/mistrea11.pdf

\section{Notation:}

$\begin{array}{ll}\mathrm{Y} & \text { observed outcome } \\ \mathrm{T}^{*} & \text { actual treatment } \\ \mathrm{T} & \text { reported treatment } \\ \mathrm{t}=1 & \text { receiving treatment } \\ \mathrm{t}=0 & \text { no treatment } \\ \mathrm{Y}(\mathrm{t}) & \text { outcome from treatment } \mathrm{T}^{*}=\mathrm{t} \\ \mathrm{X} & \text { vector of observable covariates }\end{array}$

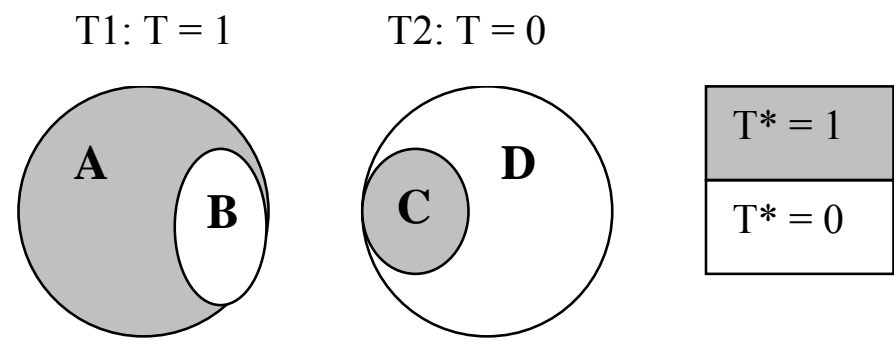

\section{Definitions:}

$$
\begin{aligned}
& \mathrm{p}_{0}(\mathrm{x})=\mathrm{E}\left[\mathrm{I}\left(\mathrm{T}^{*}=0\right) \mid \mathrm{X}=\mathrm{x}, \mathrm{T}=0\right]=\mathrm{D} /(\mathrm{C}+\mathrm{D})=\mathrm{D} / \mathrm{T} 2 \quad(=0.89) \\
& \mathrm{p}_{1}(\mathrm{x})=\mathrm{E}\left[\mathrm{I}\left(\mathrm{T}^{*}=1\right) \mid \mathrm{X}=\mathrm{x}, \mathrm{T}=1\right]=\mathrm{A} /(\mathrm{A}+\mathrm{B})=\mathrm{A} / \mathrm{T} 1 \quad(=0.65) \\
& \rightarrow \text { the relative sizes of groups " } \mathrm{T}=1 \text { " and " } \mathrm{T}=0 \text { " do not matter for the calculation } \\
& \text { of } \mathrm{p}_{0}(\mathrm{x}) \text { and } \mathrm{p}_{1}(\mathrm{x}) \\
& \mathrm{b}_{0}(\mathrm{x})=\mathrm{E}\left[\mathrm{I}(\mathrm{T}=1) \mid \mathrm{X}=\mathrm{x}, \mathrm{T}^{*}=0\right]=\mathrm{B} /(\mathrm{B}+\mathrm{D}) \\
& \mathrm{b}_{1}(\mathrm{x})=\mathrm{E}\left[\mathrm{I}(\mathrm{T}=0) \mid \mathrm{X}=\mathrm{x}, \mathrm{T}^{*}=1\right]=\mathrm{C} /(\mathrm{A}+\mathrm{C}) \\
& \rightarrow \text { the relative sizes of groups " } \mathrm{T}=1 \text { " and " } \mathrm{T}=0 \text { " do matter for the calculation of } \\
& \mathrm{b}_{0}(\mathrm{x}) \text { and } \mathrm{b}_{1}(\mathrm{x}) \\
& \mathrm{r}^{*}(\mathrm{x})=\mathrm{E}\left[\mathrm{T}^{*} \mid \mathrm{X}=\mathrm{x}\right] \\
& \mathrm{h}_{\mathrm{t}}{ }^{*}(\mathrm{x})=\mathrm{E}\left[\mathrm{Y} \mid \mathrm{X}=\mathrm{x}, \mathrm{T}^{*}=\mathrm{t}\right]=(\text { from assumption } \# 2 \text { below }) \mathrm{E}\left[\mathrm{Y} \mid \mathrm{X}=\mathrm{x}, \mathrm{T}^{*}=\mathrm{t}, \mathrm{T}\right] \\
& \tau^{*}(\mathrm{x})=\mathrm{E}\left[\mathrm{Y} \mid \mathrm{X}=\mathrm{x}, \mathrm{T}^{*}=1\right]-\mathrm{E}\left[\mathrm{Y} \mid \mathrm{X}=\mathrm{x}, \mathrm{T}^{*}=0\right]=\mathrm{h}_{1} *(\mathrm{x})-\mathrm{h}_{0} *(\mathrm{x})=(\text { from assumption \#1 } \\
& \text { below) } \mathrm{E}[\mathrm{Y}(1)-\mathrm{Y}(0) \mid \mathrm{X}=\mathrm{x}] \rightarrow \text { the average treatment effect } \\
& \tau(\mathrm{x})=\mathrm{E}[\mathrm{Y} \mid \mathrm{X}=\mathrm{x}, \mathrm{T}=1]-\mathrm{E}[\mathrm{Y} \mid \mathrm{X}=\mathrm{x}, \mathrm{T}=0]
\end{aligned}
$$




\section{Assumptions (pp. 5-7 in Lewbel 2003):}

1. unconfoundedness: $\mathrm{E}\left[\mathrm{Y}(\mathrm{t}) \mid \mathrm{T}^{*}, \mathrm{X}\right]=\mathrm{E}[\mathrm{Y}(\mathrm{t}) \mid \mathrm{X}] \rightarrow$ treatment group membership has no effect on outcomes other than through the effects of treatment itself $\rightarrow$ O.K.

2. $\mathrm{E}\left[\mathrm{Y} \mid \mathrm{X}, \mathrm{T}^{*}, \mathrm{~T}\right]=\mathrm{E}\left[\mathrm{Y} \mid \mathrm{X}, \mathrm{T}^{*}\right] \rightarrow$ assignment into the treatment group has no effect on outcomes when true treatment group membership is controlled for $\rightarrow$ O.K.

3. i) $\quad \mathrm{b}_{0}(\mathrm{x})+\mathrm{b}_{1}(\mathrm{x})<1$

$$
\begin{aligned}
& \left(b_{0}(x)+b_{1}(x)=0.35 * T 1 /(0.35 * T 1+0.89 * T 2)+0.11 * T 2 /(0.11 T 2+0.65 T 1)\right. \\
& =\left(0.0385 * T 1 * T 2+0.2275 * T 1^{2}+0.0385^{*} T 1 * T 2+0.0979 T 2^{2}\right) / \\
& \left.\left(0.0385 * T 1 * T 2+0.2275 * T 1^{2}+0.5785 * T 1 * T 2+0.0979 T 2^{2}\right)<1\right) \\
& \rightarrow \text { O.K. }
\end{aligned}
$$

ii) $\quad \mathrm{E}[\mathrm{T} * \mid \mathrm{X}=\mathrm{x}, \mathrm{T}=1] \neq \mathrm{E}[\mathrm{T} * \mid \mathrm{X}=\mathrm{x}, \mathrm{T}=0]$

$\left(E\left[T^{*} \mid X=x, T=1\right]=0.65 \neq E\left[T^{*} \mid X=x, T=0\right]=0.11\right)$

$\rightarrow$ O.K.

iii) $\quad 0<\mathrm{r}^{*}(\mathrm{x})<1$

$$
\mathrm{r}^{*}(\mathrm{x})=(\mathrm{A}+\mathrm{C}) /(\mathrm{A}+\mathrm{B}+\mathrm{C}+\mathrm{D}) \rightarrow \text { O.K. }
$$

4. $\tau(\mathrm{x})$ is identified, i.e., consistently estimated

\section{Derivation (pp. 24-25 in Lewbel 2003):}

$$
\begin{aligned}
& \mathrm{E}[\mathrm{Y} \mid \mathrm{X}=\mathrm{x}, \mathrm{T}=1]=\mathrm{E}\left[\mathrm{Y} \mid \mathrm{X}=\mathrm{x}, \mathrm{T}=1, \mathrm{~T}^{*}=0\right] * \operatorname{Pr}(\mathrm{T} *=0 \mid \mathrm{X}=\mathrm{x}, \mathrm{T}=1)+\mathrm{E}[\mathrm{Y} \mid \mathrm{X}=\mathrm{x}, \mathrm{T}=1 \text {, } \\
& \left.\mathrm{T}^{*}=1\right] * \operatorname{Pr}\left(\mathrm{T}^{*}=1 \mid \mathrm{X}=\mathrm{x}, \mathrm{T}=1\right)=\mathrm{h}_{0} *(\mathrm{x})\left[1-\mathrm{p}_{1}(\mathrm{x})\right]+\mathrm{h}_{1} *(\mathrm{x}) \mathrm{p}_{1}(\mathrm{x}) \\
& \mathrm{E}[\mathrm{Y} \mid \mathrm{X}=\mathrm{x}, \mathrm{T}=0]=\mathrm{E}\left[\mathrm{Y} \mid \mathrm{X}=\mathrm{x}, \mathrm{T}=0, \mathrm{~T}^{*}=0\right] * \operatorname{Pr}\left(\mathrm{T}^{*}=0 \mid \mathrm{X}=\mathrm{x}, \mathrm{T}=0\right)+\mathrm{E}[\mathrm{Y} \mid \mathrm{X}=\mathrm{x}, \mathrm{T}=0, \\
& \left.\mathrm{T}^{*}=1\right]^{*} \operatorname{Pr}\left(\mathrm{T}^{*}=1 \mid \mathrm{X}=\mathrm{x}, \mathrm{T}=0\right)=\mathrm{h}_{0} *(\mathrm{x}) \mathrm{p}_{0}(\mathrm{x})+\mathrm{h}_{1} *(\mathrm{x})\left[1-\mathrm{p}_{0}(\mathrm{x})\right] \\
& \rightarrow \tau(\mathrm{x})=\mathrm{h}_{0} *(\mathrm{x})\left[1-\mathrm{p}_{1}(\mathrm{x})\right]+\mathrm{h}_{1} *(\mathrm{x}) \mathrm{p}_{1}(\mathrm{x})-\mathrm{h}_{0} *(\mathrm{x}) \mathrm{p}_{0}(\mathrm{x})-\mathrm{h}_{1} *(\mathrm{x})\left[1-\mathrm{p}_{0}(\mathrm{x})\right] \\
& =\mathrm{h}_{0} *(\mathrm{x})\left[1-\mathrm{p}_{0}(\mathrm{x})-\mathrm{p}_{1}(\mathrm{x})\right]+\mathrm{h}_{1} *(\mathrm{x})\left[-1+\mathrm{p}_{0}(\mathrm{x})+\mathrm{p}_{1}(\mathrm{x})\right]=\left[\mathrm{h}_{1} *(\mathrm{x})-\mathrm{h}_{0} *(\mathrm{x})\right]\left[\mathrm{p}_{0}(\mathrm{x})+\mathrm{p}_{1}(\mathrm{x})-1\right] \\
& =\tau^{*}(\mathrm{x})\left[\mathrm{p}_{0}(\mathrm{x})+\mathrm{p}_{1}(\mathrm{x})-1\right] \\
& \rightarrow \tau^{*(\mathrm{x})}=\tau(\mathrm{x}) /\left[\mathrm{p}_{0}(\mathrm{x})+\mathrm{p}_{1}(\mathrm{x})-1\right]
\end{aligned}
$$$$
\left(\tau^{*}(x)=\tau(x) /[0.89+0.65-1]=\tau(x) / 0.54\right)
$$ 